\title{
Microstructure and Strain Hardening in Tensile-Tested Fe-Mn-Al-Si Steels
}

\author{
D. T. Pierce, ${ }^{1,2}$ J. A. Jiménez, ${ }^{3} J$. Bentley, ${ }^{4}$ D. Raabe, ${ }^{5}$ and J. E. Wittig, ${ }^{1}$
}

${ }^{1}$ Interdisciplinary Materials Science, Vanderbilt University, PMB 351683, Nashville, TN 37232, USA

${ }^{2}$ Now at: Adv. Steel Processing \& Products Res. Ctr., Colorado School of Mines, Golden, CO 80401, USA

${ }^{3}$ Centro Nacional de Investigaciones Metalúrgicas (CSIC), Avda Gregorio del Amo 8, 28040-Madrid, Spain

${ }^{4}$ Microscopy and Microanalytical Sciences, PO Box 7103, Oak Ridge, TN 37831-7103, USA

${ }^{5}$ Max-Planck-Institut für Eisenforschung, Max-Planck-Straße 1, D-40237 Düsseldorf, Germany

The exceptional combination of strength, ductility and strain hardening of high-Mn transformation- and twinning-induced plasticity (TRIP/TWIP) steels makes them appealing for automotive applications (e.g. vehicle weight reductions through down-gauging and room-temperature (RT) forming of complex shaped parts). The present study uses three Fe-22/25/28Mn-3Al-3Si alloys to investigate the effect of changes in stacking-fault energy (SFE) on the evolution of microstructure and mechanical properties during RT tensile deformation. The SFEs were previously measured by analysis of partial-dislocation separations using weak-beam dark-field TEM [1-4] that ultimately [1] incorporated single-crystal elastic constants measured on polycrystalline specimens by a novel nano-indentation method $[5,6]$. The RT SFEs of the Fe-22/25/28Mn-3Al-3Si alloys are $15 \pm 3,21 \pm 3$, and $39 \pm 5 \mathrm{mJm}^{-2}$, respectively. Details of alloy and specimen preparation, tensile testing (see Figure 1), and specimen preparation for transmission electron microscopy (TEM) have been described elsewhere [1-4]. Microstructural characterization included optical microscopy, X-ray diffraction and TEM (performed at $200 \mathrm{kV}$ with a Philips CM20T).

The following important conclusions were drawn from this work: (i) A SFE of 15 mJm² (Fe-22Mn-3Al$3 \mathrm{Si}$ ) resulted in a deformation microstructure dominated by highly planar slip, suppression of dislocation cross-slip, and $\alpha_{\mathrm{bcc}} / \varepsilon_{\mathrm{hcp}}$-martensite transformation as the dominant secondary deformation mechanism (see Figure 2). The onset of grain refinement due to the formation of multiple variants of $\varepsilon_{\mathrm{hcp}}$-martensite within any given grain occurs from the beginning of plastic deformation and provides superior work hardening at low and intermediate strains (0-0.34 true strain), and the highest strength (687 $\pm 7 \mathrm{MPa})$ but lowest elongation (85 $\pm 3 \%$ ) of the three alloys. (ii) A SFE of $21 \mathrm{mJm}^{-2}$ (Fe-25Mn-3Al-3Si) resulted in a dislocation structure that exhibits both planar and wavy characteristics. The formation of both $\varepsilon_{\mathrm{hcp}}-$ martensite and mechanical twinning (see Figure 3) results in excellent strain hardening in the initial, intermediate and final stages of deformation, along with the largest elongation $(91 \pm 1 \%)$ of the three alloys, albeit with intermediate strength (642 $\pm 7 \mathrm{MPa})$. (iii) At low strains (0 to 0.1 true strain), a SFE of $39 \mathrm{mJm}^{-2}$ (Fe-28Mn-3Al-3Si) facilitates greater dislocation cross slip and mobility resulting in the formation of a dislocation cell structure (see Figure 4a) and reduced strain hardening compared to that of lower SFE alloys. Formation of $\varepsilon_{\mathrm{hcp}}$-martensite is completely suppressed, but mechanical twinning (see Figure $4 \mathrm{~b}$ ) enhances the strain hardening from $\sim 0.1$ true strain to failure, resulting in excellent ductility $(87 \pm 2 \%)$ but the lowest strength $(631 \pm 5 \mathrm{MPa})$ of the three alloys. (iv) The range of SFE from 15 to 39 $\mathrm{mJm}^{-2}$ results in an excellent product of strength and elongation (55-58 GPa\%) with only small variations in strength and ductility, despite the transitioning of the steels from TRIP- to TWIPdominated behavior. Comparisons with literature data indicate that strength and ductility decrease significantly above a SFE of $\sim 40 \mathrm{mJm}^{-2}$, corresponding to a reduction in mechanical twinning [7].

References:

1. D T Pierce, J A Jiménez, J Bentley, D Raabe, C Oskay, and J E Wittig, Acta Mater 68(2014)238-53

2. D T Pierce, J Bentley, J A Jiménez and J E Wittig, Scripta Mater 66(2012)753-6

3. D T Pierce, J Bentley, J A Jiménez and J E Wittig, Microsc Microanal 17-Suppl 2(2011)1888-9

4. D T Pierce, J Bentley, J A Jiménez and J E Wittig, Microsc Microanal 18-Suppl 2(2012)1894-5

5. D T Pierce, K Nowag, A Montagne, J A Jiménez, J E Wittig and R Ghisleni, Mater Sci Eng A578(2013)134-9

6. D T Pierce, K Nowag, A Montagne, J A Jiménez, J E Wittig and R Ghisleni, Microsc Microanal 19-Suppl 2(2013)1052-3

7. This work was sponsored by the US National Science Foundation Division of Materials Research, under grant

DMR0805295 and by the Ministry of Science and Innovation of Spain, under Grant MAT2012-39124. DTP

acknowledges support for extended visits to CENIM, Madrid and MPI, Düsseldorf. JB acknowledges his appointment as Adjoint Professor of Materials Science at Vanderbilt University. 

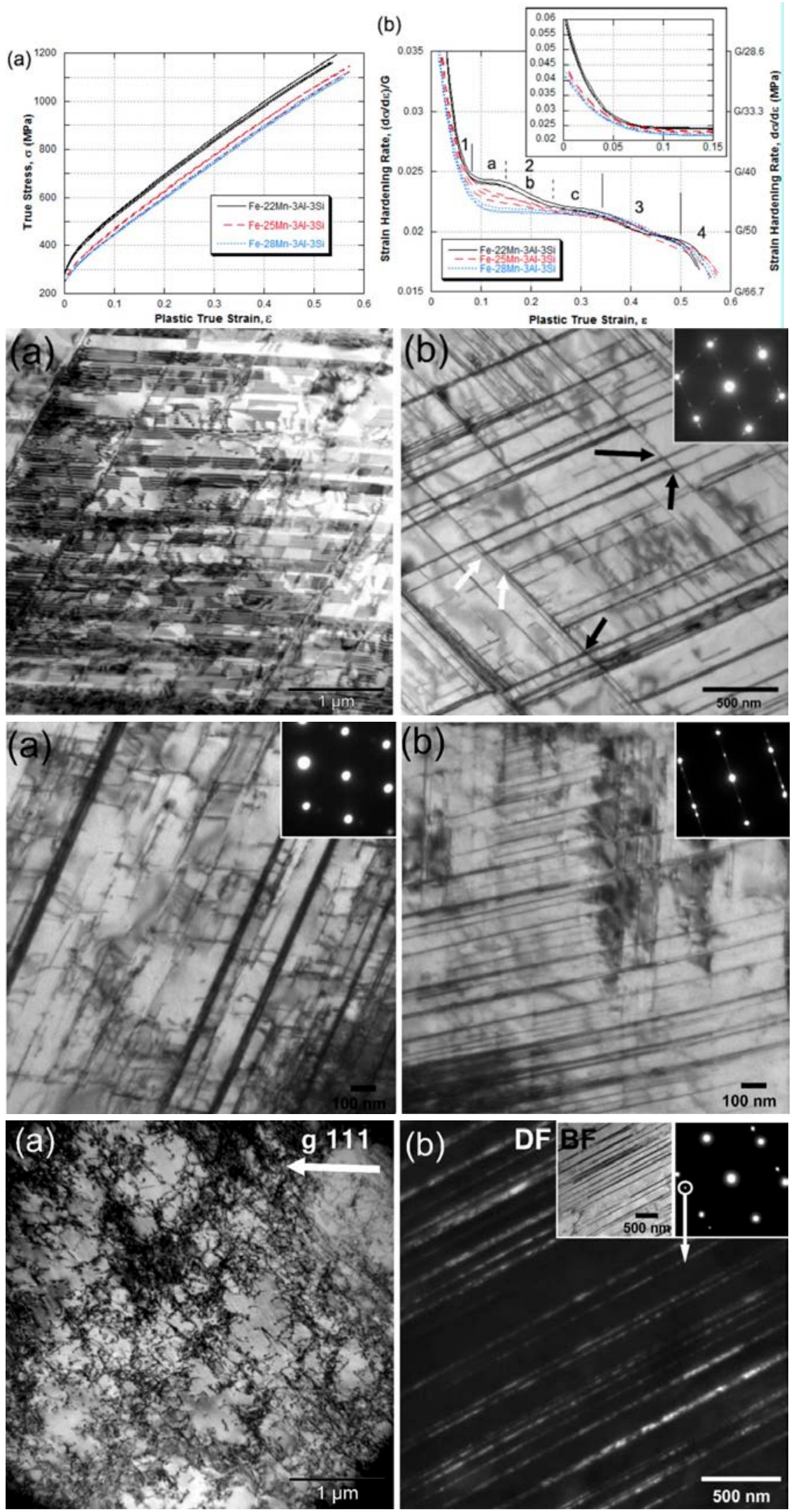

Figure 1. RT tensile data (3 tests for each alloy) at $4 \times 10^{-4} \mathrm{~s}^{-1}$ using subsized flat specimens with 20-mm gauge length, 5-mm width and 1.5mm thickness. (a) True stress vs true strain. (b) Strain-hardening rate, normalized by the experimental shear modulus ( $\mathrm{G}=69 \mathrm{GPa})$, vs true strain. Data in (b) are derivatives of $9^{\text {th }}$ order polynomial fits of data in (a). 4 stages (plus 3 sub-stages for the $22 \% \mathrm{Mn}$ alloy) of strain hardening are labeled.

Figure 2. TEM BF images of $22 \% \mathrm{Mn}$ alloy after 0.1 plastic true strain. (a) High density of overlapping SFs (inclined $\varepsilon_{\mathrm{hcp}}$-martensite laths) and (b) grain with 2 variants of edge-on $\varepsilon_{\mathrm{hcp}}{ }^{-}$ martensite laths oriented with $(111)_{\gamma}\left\|(0001)_{\varepsilon} /[1-10]_{\gamma}\right\|[1-210]_{\varepsilon}$ where $\gamma$ indicates the austenite matrix. SAD pattern (inset) was recorded at a $<110>$ zone whereas the $\mathrm{BF}$ image was recorded slightly off the zone axis in a two-beam condition. Arrows indicate lath intersections (black) or terminations (white).

Figure 3. 25\%Mn alloy deformed to 0.1 true strain. BF images of (a) mechanical twinning and (b) fine $\varepsilon_{\mathrm{hcp}}-$ martensite lath structure. The SAD patterns (inset) were recorded at $<110>$ zones whereas the BF images were recorded a few degrees off axis in two beam conditions. SAD patterns show twin reflections at $1 / 3$ positions along $<111>$ rows except through the central spot or $\varepsilon_{\mathrm{hcp}}$-martensite reflections also along $<111>$ rows but based on a rectangular net with $(0001)_{\varepsilon}$ at $\sim 1 / 2<111>$ position.

Figure 4. 28\%Mn alloy deformed to 0.1 true strain. (a) BF image of grain with dislocation cell structure. (b) DF image of mechanical twins using a $\{111\}$ twin refection. The SAD pattern and $\mathrm{BF}$ image (insets) were recorded at a $<011>$ zone and slightly off axis in a two-beam condition, respectively. 25 and $100 \%$ of grains contain mechanical twins for true strains of 0.10 and 0.18 , respectively. High densities of dislocations are present in inter-twin regions, especiallv near twin/matrix interfaces. 